ARTICLE

\title{
Counterurbanisation: why settled families move out of the city again
}

\author{
Lia Karsten ${ }^{1}$
}

Received: 20 August 2019 / Accepted: 17 March 2020 / Published online: 10 April 2020

(c) The Author(s) 2020

\begin{abstract}
After decades of massive family suburbanisation, we have observed a steady increase in family households in various European capitals, including Amsterdam. Currently, the number of Amsterdam families is still increasing, however the number of families leaving the city is also growing and again on the rise. How can we explain this change, particularly for settled families that used to avoid outmigration? Empirical results are obtained from a qualitative study of urban middle class parents with children of primary school age who have recently moved out of Amsterdam. The results reveal that the shortage in the supply of family housing at a reasonable price for all families is the prime incentive to move. Underneath shared financial argumentations, however, we can distinguish three types of families that have specific motivations to move: pragmatic movers, displaced families and happy movers. The motivations to move are strongly related to different parental narratives of a 'good childhood environment'. The results reveal further that the current displacement patterns are not only class-driven but include highly educated double-income family households. This paper ends with a short discussion of how to prevent cities from becoming homogeneous, rich non-family places.
\end{abstract}

Keywords Counterurbanisation · Urban family housing · Urban childhood · Displacement

President SCP/ Child in the City https://www.childinthecity.org/about-us/the-scientific-program-commi ttee/

Author of the most cited paper in Children's Geographies: https://www.tandfonline.com/toc/cchg20/ current\#b7689c1d-7975-46ed-aaf9-3a2939834054-b44f4d8e-2a9f-4411-ae51-0b3c835c6698

Lia Karsten

c.j.m.karsten@uva.nl

https://www.uva.nl/profile/c.j.m.karsten

1 University of Amsterdam, Nieuwe Achtergracht 166, Post Box 15718, 1001 NE Amsterdam,

The Netherlands 


\section{Introduction}

In recent decades, we have observed a considerable increase in urban family households in several European capital cities (Butler 2003; Boterman et al. 2010; Rerat 2012; Authier and Lehman-Frisch 2013; Frank and Weck 2018). These new urban families are indicated in the literature as young urban professional parents (YUPPs) to distinguish this group from the urban-oriented childless yuppies (Karsten 2007). Current urbanites and city lovers are not limited to residents without children: families also define themselves as belonging to the city and they firmly reject all "traditional" ideas about the city as an unattractive place to raise children. From Stockholm to Parish and from London to Helsinki, young families manifest themselves as new urban figures (Lilius 2014).

Also in Amsterdam, a steady increase in family households can be established in inner city neighbourhoods. Very recently, however, the data on Amsterdam family households and family outmigration are changing again. While the total number of family households continues to experience modest growth, from 2014 onwards the outmigration of families is also increasing (Booi and Karsten 2019). Will this pattern become a new trend and signify a return to traditional (suburban) family life with its anti-urban orientation (Bell 1968; Mazanti 2007; Aner 2016)? What accounts for the recent family outmigration statistics? To learn more about this new phenomenon, we performed research on families who have recently moved out of Amsterdam. We were particularly interested in young families with school-age children: settled families. The literature learns that settled people do not move (Fischer and Malmberg 2001) as they do not want to relinquish established life with children in primary school, arranged day care, and well-known school friends. We assumed that they would have strong reflections on the decision to leave. We decided to focus our research on the group of settled families. Why do settled families leave Amsterdam?

To answer this question, we will examine the literature about families, cities and counterurbanisation followed by information about the research location, population and methods. The results are structured in three sections that reflect three different types of outmigrating families based on parental narratives about what is considered to be a good childhood environment. This paper ends with conclusions, additions to the literature and a short discussion on urban housing policies.

\section{Literature}

According to Mitchell (2004), the concept of counterurbanisation suffers from definitional confusion. Generally, the concept points to a process of population deconcentration and is considered the opposite of urbanisation. In this research, we conceptualised counterurbanisation as the process of urban outmigration, which encompasses all movements to less urbanised areas, including both rural locations and suburban locations. To understand why families relocate from the city to less densely populated areas, Mitchell (2004) has constructed a three-fold classification of movers based on motivations to leave the city. The first group is referred to as ex-urbanites. Ex-urbanites are relatively well-to-do urbanites who wish to live outside the city but do not want to entirely relinquish their urban life. Their optimal situation is to live close to the city and maintain connections with the city by continuing work and other urban activities, such as cultural and social outings. Ex-urbanites do not prefer to live in very peripheral regions as retaining their urban connections 
would become too complicated. Ex-urbanites are considered to be pragmatic and seek 'only' better and bigger housing within reasonable commuting times (High 2019; Hjorthol and Bjornskau 2005). The second group is referred to as displaced urbanites. These former urbanites feel displaced as they did not want to leave the city, but felt forced to do so for reasons of work and/or housing. Displaced urbanites or urban dropouts feel financially forced to leave the city and leave with feelings of regret. The third group of counter urbanites, the anti-urbanites, have motivations that stem from strong anti-urban feelings. They consider the city as an urban jungle in the first place and want to escape all supposed negative elements such as crime, congestion, unsafe conditions, pollution etc. Different from the ex-urbanites, they want to not only reside outside the city but also work in less urban environments and establish a completely new life. Anti-urbanites seek the rural ideal. This element of ideals that drive people to move out of the city is also employed by Rivera Escribano (2007). She distinguishes three residential strategies in urban-rural relocations. All three strategies include elements of anti-urbanism and reflect different stages of successfully realising a life elsewhere in rural areas. The first strategy is referred to as pragmatic dystopia: the new location of living is a relatively short distance from the city. The second strategy of refuge utopia is a form of long-distance commuting. Only the third strategy of deep-rooted utopia realises the dream of living and working in really peripheral places.

Young families are generally seen as a special category in counterurbanisation processes. The literature explains the counterurbanisation of young families with the life-cycle theory, which has two components: the housing and the environment (Mulder and Hooimeijer 1999; Aner 2016). Both components are considered to have push factors (out of the city) and pull factors (into less urbanised areas). With a growing family, the need for a bigger house is evidently clear. Cities do not provide many family houses/apartments and the small availability of bigger housing in cities has a high price. For many families, this price is too high. Changes in the life cycle, growing as a family, is considered the main incentive for families to move out of the city (push factor) to places where the supply of bigger housing is more abundant and less expensive (pull factor).

The need for bigger housing is strongly related to the wish for a 'good quality environment'. Settled families have children who want to play outdoors, travel to school and explore the neighbourhood. These desires motivate families to seek quieter, greener and safer environments. Cities generally have only limited play and green facilities, often lack (traffic) safety and have an overload of people in certain locations. Emmelkamp (2004) shows that parents are inclined to define cities as urban jungles and have idyllic ideas about the countryside (Valentine 1997). This explains why parents prefer 'rural-like' neighbourhoods with streets that feature green spaces, low traffic volumes and broad sidewalks. But again, like with family housing, in cities the supply of this type of urban haven neighbourhoods remains limited. Urban families that cannot afford adequate family housing and/or urban haven-like neighbourhoods decide to start living elsewhere: they counterurbanise.

Life-cycle theory is thus helpful to understand why families leave the city; however, two questions remain. First, families are not free to choose any place to live. Financial barriers are evident, and in addition: families are bound in time and space. Particularly, dual-earner families are vulnerable regarding their daily commutes. These families have to combine both care and career on a daily basis and cannot afford to have long commutes. The growing number of working parents has increased dual earner families' interest in living in urban areas near work and facilities (High 2019; Hjorthol and Bjornskau 2005; Karsten 2007; Jarvis 2005). Time-spatial considerations limit the explanation offered by the life-course theory. A second limitation of the life-cycle theory is related to definitions 
of 'big enough housing' and 'good quality environment' to raise children. Families use different discourses on what constitutes a good environment to raise children. Parents who define the city as a good place to grow up probably aim to stay in the city, while negative discourses of the city as an urban jungle will be a trigger to leave the city (push). In the same way, discourses on the countryside have a role: to what extent do families define rural areas as idyll places to raise children (pull)? Parental discourses on what a good childhood environment should be, can be considered to have an important influence on the decision to stay or leave. These parental discourses reflect the habitus (Bourdieu 1984). Habitus is a complex of ingrained perceptions of how people conceive the world, including the residential environment. What is the perception of parents on cities, villages and suburbs in relation to a good childhood? Habitus informs people's spatial discourses but is not freely chosen. Habitus is built on a person's accumulated economic, social and cultural capital from early childhood onwards. Regarding housing, economic capital is the first condition to live somewhere: it organizes financial access. But also social and cultural capital is important in the way that the residential environment is assessed, accessed and consumed. Research shows, for example, that urban living is more appreciated by families with relatively high cultural capital than by families with relatively high economic capital (Boterman 2012). The life cycle can be described as a process of continually building on different capitals in specific combinations that feed parental dispositions and discourses on what a good childhood environment should be. Parental spatial discourses on both the city and the new-less urban-destination feed the legitimations to stay or to leave. In this paper, we aim to understand the differentiated motivation to leave the city as a place to raise children.

Migration literature suggests that movements to new areas entail compromises. Idyllic living situations are sought but utopia is almost never realised. Partners do not always agree with each other. Housing supply is not always as favourable as predicted. Children do not start to live the idyllic outdoor life as hoped (Tillberg 2002). New communities are not as welcoming as expected (Brunt 1974; Elias and Scotson 1994; Richards 1990; Valentine 1997; Rivera Escribano 2007). In a second paper on this study, we will elaborate on the gains and losses that guide the relocation of a family.

\section{Research location and methods}

The housing market in Amsterdam has always been relatively tight; however, after the crisis (2008-2013), the Amsterdam housing market became extremely tight with a growing demand and fast rising prices both in the private rental sector and the owner occupied housing sector. Between 2000 and 2019, the Amsterdam population increased from 731.289 to 862.987 , including a growth of family households from 94.849 to 115.253 (Booi and Karsten 2019). The steadily growing group of Amsterdam residents have increasingly encountered the problem of obtaining appropriate housing, which has further worsened since the increase in short-term rentals, including AirBNB. The number of tourists that visit Amsterdam and the number of expats moving to Amsterdam to work has cumulated considerably over the last years (Solman 2017; Sondermeijer 2019). This external competition on the housing market has not only negative effects on the accessibility of affordable housing for Amsterdam residents, but also manifests itself in a busier public space. An increasing number of people populate in formerly quiet neighbourhoods. Local newspapers are continually reporting that Amsterdam is becoming 'too crowded'. Many locals are 
complaining about the 'invasion' of tourists, particularly residents who have been living in the city for years (Pinkster and Boterman 2017).

It may not come as a surprise, that parallel to a growing number of Amsterdam family households, we have also observed a growing outmigration of family households. From 2017 to 2018, 17\% of all family households in Amsterdam moved out of the capital compared with $11 \%$ of all family households for the period 2013-2014 (Booi and Karsten 2019).

In this increasingly pressured city, we have interviewed parents in 18 households, most of who were females. During the interview, however, we collected data of both parents and children. We selected 'settled' dual-earner families, with at least one child who was at least 4 years old, which is the age that children in the Netherlands go to primary school. All parents are working parents (most parents have part-time jobs) whose ages range from 36 to 52 . With their educational background (mainly academic) and income situation (two incomes), they can be classified as middle class to higher middle class. Nearly all of the parents have a Dutch background and used to live in Amsterdam for already long periods of time, varying from 10 to 38 years. Some parents were born and bred in Amsterdam. The interviews (minus 2) are all held in spring 2018 in the newly acquired house, 6 months to 2 years after the relocation. The respondents are recruited from the social networks of the interviewers and social media. The interviews were held for one and a half to $2 \mathrm{~h}$ and consisted of both a qualitative part and a quantitative (survey) part about changes in time-space behaviour. All interviews were fully transcribed, coded and analysed. Names of the respondents are anonymised.

Until the moment of relocation, the interviewees resembled the YUPPS who were previously described: young urban professional parents living within the Amsterdam ring (Karsten 2014). After a long period of living in Amsterdam, they decided to leave the city. Their leaving was likely attributed to the housing situation and their need for more space at this stage in the life cycle. All of the interviewed families indeed improved their housing situation: they moved to a bigger house with more rooms, had a private garden after they moved (before: 8 of 18 households) and acquired owner occupied housing (before: 13 of 18 households).

\section{Analysis}

With the help of the literature we concluded that the life-cycle theory explains the family counterurbanisation, only partially. Our research indeed shows families that are at a specific stage of their lives and leave the city as they are in need of bigger and better housing that they cannot find or afford in capital cities. The interviewed families do not differ in this respect. However, the interviewed families turned out to vary in their motivations to leave related to their narratives on what a child-friendly environment should be. Analysing the interviews and building on both Mitchell (2004) and Rivera Escribano (2007), in this research we can distinguish three different types of outmigrating families (Table 1). The first type of family consists of pragmatic movers. Families that belong to this type consider their relocation mainly in more practical terms of space and time. Families that belong to the second type of displaced urbanites reveal feelings of regret of losing their binds with Amsterdam. The third group of happy movers was glad that they had the chance to leave the capital city. These three differentiated reflections on the decision to leave turned out to be strongly related to 


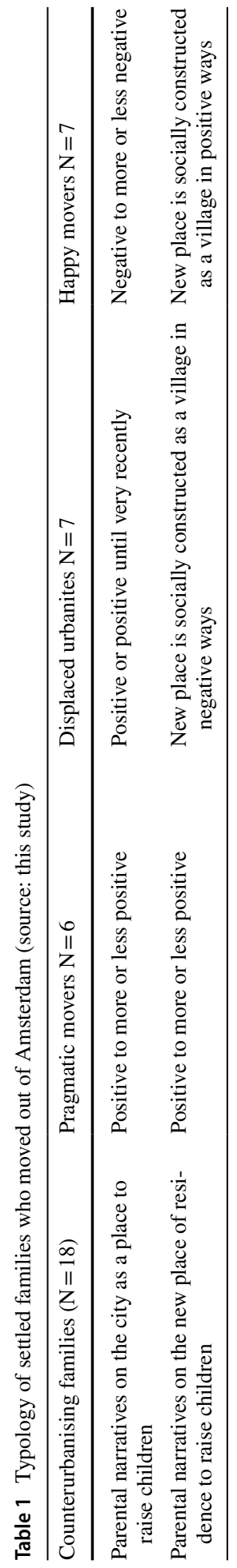


parental discourses about good childhood environments. As shown in Table 1 distinguishing three types of counterurbanising families is based on the parental assessment of both the city and the new place of residence as a place to raise children. On the basis of this small scale study, we cannot attribute much significance to the numerical distribution of the three types.

These three groups and their reflections on the decision to leave will be highlighted in more detail in the next three sections. Each of the sections will be followed by a portrait of one family that is considered to be a good representative for the specific type.

\section{Pragmatic movers}

Pragmatic movers are families who have always liked living in Amsterdam. They define Amsterdam in positive terms with regards to raising children but are not afraid to mention some downsides. Stien, who is a mother of three, explains: "I was raised myself in Amsterdam and that was totally nice. It is a nice city where you can have nice adventures and where many nice people live. I also think that urban live brings you a certain amount of street wisdom that you will miss when you are not raised urban...So, no nothing wrong". She continues with some negative observations of urban living: "In Amsterdam, children are not allowed to go away from their parents more than a few meters". Children's limited freedom of movement and the constant need for parental supervision was mentioned by many of the counterurbanites as the greatest disadvantage of urban living. The pragmatic movers, however, do not express this disadvantage as the greatest reason to leave Amsterdam. They indicate the need for bigger housing as their prime trigger. The homeowners among the pragmatic movers narrate the sharp rise in housing prices that motivated them 'to sell now' and look for a new house elsewhere. The renters observed the same rising prices and felt that they should make the next step before it was too late: they expected the price of housing to increase even more in the future. Both groups started to look for bigger housing in Amsterdam but soon discovered that they could not make progress they wanted or only at a too high cost. They continued their search by visiting towns and cities nearby Amsterdam and/ or well accessible by public transport. Time-spatial reasons were distinct in the interviews. Almost all pragmatic movers were dependent on the Amsterdam labour market before their relocation and wanted to continue working in Amsterdam afterwards. All succeeded. In more general ways, pragmatic movers wanted to secure their relationship with Amsterdam. After their relocation, families belonging to this type organised bikes to be used in Amsterdam and places to sleep for themselves and their children (friends, family). In so doing, they reveal a pragmatic viewpoint directed at continuing their lives as urbanites but now living outside the capital. Their new residences were appreciated in terms of bigger housing in more rural like neighbourhoods but the downsides are also mentioned. Heike, a mother of two, moved to $\mathrm{H}$. with its fast train connection to Amsterdam: "There are days that I think: what nice that we live here, and also sometimes days that I think: why have we left?" She then continues with complains about the missing of specific schools, interesting people, cultural facilities in the new place of residence, but concludes with: "...then I think: if I want to go to the cinema, I go! To Amsterdam, it is only half an hour by train”! 


\subsection{Pragmatic movers portrait}

Brenda (interviewee) and Frits moved with their 6 year old daughter Wanda to a village near Amsterdam. As a family, they had been living in Amsterdam for more than 12 years in what she calls a very nice neighbourhood. She describes Amsterdam as a good place to raise children and narrates her urban family adventures: cycling to Artis (the zoo), the nice toddler dancing club and other places for fun. School was nearby, but as Brenda tells she or her partner had always to accompany Wanda even over small distances. In the new village that isn't any more necessary and that feels as relief to Brenda. She is happy with her quiet new place of residence, which creates more freedom of movement for her family. But Brenda also mentions some disadvantages of the new residential location, which mainly pertains to education: only one ordinary public school exists in the village, while her daughter used to attend an Amsterdam Montessori school. Both Brenda and her husband are still working in Amsterdam. They do not want to miss the big city. Therefore, they bought a house near Amsterdam with good public transport connections. In summer, it is even possible for them to go by bike to their work. Brenda and her husband continue reading the Amsterdam newspaper that is on the kitchen table when the interviewer arrives. The new place of residence is constructed as part of Amsterdam: according to Brenda it feels like an outer borough of Amsterdam. Brenda concludes the interview by saying that they had a nice time as a family in Amsterdam, but now they are starting a new period in life with new charms and disadvantages.

\section{Displaced urbanites}

Amsterdam as a gentrifying city is both growing and in the middle of a process of replacement. Some of the citizens who move out will define their outmigration as displacement, which is the case with the second type of outmigrating families. Feelings of displacement are related to either rising housing prices and/or the changing character of a neighbourhood. The rising price of housing was mentioned as the primary reason to leave by the renting families in this type. These families felt that they were 'too late' to buy a house of reasonable size and price in Amsterdam. They explained that they could not make a next step in the housing career in their beloved city due to financial reasons. These families felt forced to leave and buy a house in a less popular place for a relatively low price (for some people, with the help of parents). The second group of displaced families had already a house of their own in Amsterdam. They do not feel financially displaced but feel emotionally displaced in the first place. These families used to live in urban haven like neighbourhoods that have recently changed character due to new building constructions and/or growing tourism. Changes in their former neighbourhood generated an increase in anonymity on the street and even crime. After many years of positive residential satisfaction-including time with small children - they felt forced to leave as Ina explains: "We have lived there (Adam, lk) with lots of pleasure. But the city became much more crowded, particularly in our neighbourhood, Old West. It used to be quiet, but it has exploded to Pijp (a very touristic Amsterdam neighbourhood) level over the last 5 years. And lots of building activity because of the Hallen (new cinema complex, lk)".

The displaced families have not left due to a negative disposition to growing up in an urban area. Amsterdam as a place to raise children was mainly appreciated, at least until 
recently. Ina: "What I have always liked of Amsterdam that you can do many things quite easy. With children you generally have a little window of opportunity, they have their sleeping times, eating hours, but in Amsterdam you can easily go by bike to a museum with your child and be back in time. Or you can use the best facilities for your child: top music lessons for example. And then what I like is the diversity of people. ... The obedient citizenship where we live now, that is also very restricting. In the city, it is nice for children and good to see that that diversity exists". However, this positive narrative on Amsterdam childhood does not apply anymore to her former street. Some of the displaced families who have moved out miss the city and define their new place of residence as a village in mostly negative ways. They emphasise limited facilities, including schools, but above all they feel socially deprived: "We miss people with the same ways of thinking, it is more narrow minded village people, here". This quote was provided by Mees, who had wanted to move to bigger housing in Amsterdam but ended up living in a region outside the Randstad. Most of the displaced families 'succeed' in finding an alternative location within the region with the possibility of continuing their former jobs. Similar to the pragmatic movers, the displaced urbanites are eager to continue their relationship with Amsterdam in different ways.

\subsection{Displaced family portrait}

Inge (interviewee) — born and bred in Amsterdam-moved with husband Peter and their three children to a mid-sized city, to the north of Amsterdam. Both Inge and Peter are educated and working in the cultural sector. They used to rent a small social housing apartment in Amsterdam and have attempted for several years to exchange within the Amsterdam social housing sector. A year ago they admitted that their aim to remain in the city would not succeed and they decided to leave. Inge describes Amsterdam as a nice place to grow up with lots of memories of her own childhood. She explains that she never had the feeling of missing something during her childhood. She recognises the lack of green space and nature but realised that she had always found other things to do. In her new place of residence, she particularly misses urban culture for not only her children but also for herself and her husband. Culture pertains to film, theatre and music, but particularly, to social circles with a good mix of different people in the neighbourhood. Inge describes her new neighbours as 'village people' who control her whereabouts. She cannot get used to the new schoolyard, which only has blond children, and expresses her feelings of regret that the world has become smaller for her and her children in their new place of residence. Some of their family remained in Amsterdam and they rely on them to continue their binds with the capital. Both Inge and her husband had to change work and now have two part-time jobs, one being located in the new place of residence and the other one still in Amsterdam.

\section{Happy movers}

One of the questions in the interview was to comment on the following statement: Amsterdam is a good place to grow up. While parents that belong to the type of pragmatic movers and the type of displaced urbanites responded in (moderate) positive ways, the happy movers narrated more negative urban sentiments. They either did not agree with the statement or set clear limits: 'some Amsterdam neighbourhoods are perfectly acceptable for adults and adult ways of life'. The happy movers are not very negative about Amsterdam-they had lived there for several years - but now they have the task of raising children and that 
has changed their view on the city. The happy movers define the city as a demanding and dangerous place to live with too many restrictions for children. Susan describes her daughter who is 6 years old and did not thrive in Amsterdam: "For our daughter, the incentives in Amsterdam were too big and too many. There is such a big supply of everything and here it is much more quiet. We notice that she is much more quiet in her head now we live here". Independently of whether they have left to a small village or a medium sized city, the new place of residence is equally defined as a village and in positive ways. Drika and her two children enjoy their new environment very much: "This is a village, a real village. Instead of biking through the fumes to school, we now go through the wood. Much healthier, here". The happy leaving families had longed to leave the city but were not able to leave due to the financial crisis. These families left Amsterdam as soon as they could sell their house at a good price. Different from the first two types of families, the happy movers don't have strong emotional ties to Amsterdam. None of them was born and bred in Amsterdam. Instead, during the interview, they refer to their childhoods in more rural contexts (Cathy): "We thought do we want to live there (Amsterdam, lk) for the coming 20 years with us as family and with a second child? We have both been raised elsewhere. I grew up here (new place of residence, lk) at the coast and my husband comes from an island". Cathy and her husband decided to live in a village near the coast to the North of Amsterdam. For this family and some other the relocation meant also a return to their roots and extended family, like is the case with Cathy, "My sister lives here at the end of the street". After the birth of the children the definition of Amsterdam had changed in negative ways. That negative connotation had much to do with the missing of green and nature. Some of the happy movers had a little green place to go to (camp site, vegetable garden, community garden) when they lived in Amsterdam, but that could not compensate their feeling of missing out on nature. On the question whether they would like to return to Amsterdam when it would be possible to bring the new bigger house with them, Hilly answers: "No. No than I would miss the nature. And then again that crowdedness and the traffic and all the people, all that hurrying". Apart from positive narratives on green space, nature and health, the new village is praised for its lack of waiting lists for children's clubs and schools and its relaxed way of life with less incentives and more freedom of movement for both children and parents. The group of happy movers has less social binds with Amsterdam than the families in the other two groups, which also applies to work ties. Most families used to have either only one parent working in Amsterdam or none who worked in the capital. After the move, the dependence on the Amsterdam labour market further decreased. Three mothers changed their work to freelance work in different locations.

\subsection{Happy movers portrait}

Nico (interviewee) and Isabel had come to live in Amsterdam after they completed their studies in another city in the Netherlands. They bought a house in 2006, where their two children were born. Soon after they moved, Nico and Isabel discovered that not only the house would be too small for their children over time but also they did not like Amsterdam as a place to raise their children. Nico and Isabel disliked the crowds and the traffic and assessed the quality of Amsterdam schools to be inferior. After the birth of their children, Nico and his wife, however, felt forced to stay in Amsterdam for some more years due to the financial crisis. As soon as they could sell their house at a good price, they left. Nico and Isabel wanted a new residence in a greener part of the Netherlands: behind the fourth city of the Netherlands: Utrecht. Utrecht was not considered to be an alternative for 
Amsterdam: still too large. They moved to a new village-like town in the eastern part of the Netherlands. They value their new residential location for its ease of living, its better air quality and good education. Nico and Isabel now have a big enough house with a garden on a quiet green street. Nico continues with his work at the south of Amsterdam and Isabel started to do freelance work from home. Nevertheless they needed to buy a second car that could be used by Isabel to reach her clients. Although the children's freedom of movement has increased compared to the situation in Amsterdam, sports and other children's clubs are not within easy reach. The car is often used and now has a more prominent place in everyday family life.

\section{Conclusion and discussion}

This paper reports on a small-scale research that sought a deeper understanding of a renewed development of families that move out of the city. This moving out applies to a minority of the family households in Amsterdam (Booi and Karsten 2019), but it is a slightly growing minority. To obtain better insight into the motivations behind the new outmigration of families, we directed our research toward 'settled families' who are not expected to leave light-heartedly (Fischer and Malmberg 2001). Our research population consisted of higher educated (part-time) working parents with young children who had been living in the city of Amsterdam for a minimum of 10 years. These parents wanted to take the next step in their housing career parallel to the expansion of their family, either in number or size of children. After a short, but in most cases, extensive search for housing in Amsterdam, these parents concluded that they would not succeed in buying a bigger house in a child-friendly Amsterdam neighbourhood. This conclusion motivated them to move out of Amsterdam. Underneath the decision to leave the city different narratives are told that guided them towards their new residential locations. In this study, we constructed a typology that distinguishes three types of families who narrated three different stories about their motivation for outmigration. Crucial in the construction of the typology is the difference in the spatial discourses on raising children.

The first type of family-pragmatic movers-resemble the ex-urbanites labelled by Mitchell (2004), who follow the strategy of pragmatic dystopia described by Rivera Escribano (2007). Pragmatic movers are able to continue their lives while simultaneously make a change. They reveal strong time-spatial considerations in their search for a new residential location, as they used to have in their former statuses as urbanites or YUPPS (Karsten 2007). Without negativity, they narrate their experiences of gains and losses after the relocation. Push and pull factors are in a certain balance. Although they consider Amsterdam a suitable city to raise children, they do not disregard its disadvantages or romanticise their new place of residence. The new place is narrated as positive for the children, particularly due to their increased freedom of movement, but the parents also indicate that they miss the urban vibe and specific facilities for themselves and their children.

The second type of family - displaced families - feel primarily forced to move. These families would have liked to continue living in the city but could not achieve progress in the housing market in Amsterdam. Displaced families consist of both former renters and former owners. The group of renters felt financially displaced. These families moved out of the city although they continued to define Amsterdam as a good place to live and raise children. The second group of owners felt predominantly emotionally displaced. They did not recognise their neighbourhood anymore. Their former neighbourhood had changed 
character from an urban haven to a crowded, noisy, anonymous, and dangerous place to live. These families blame the growth of the tourist industry and notice the increase in new shops and facilities that do not serve the everyday residential needs. They had to admit that Amsterdam is not anymore the city they used to love (Pinkster and Boterman 2017). Their new place of residence is narrated as 'only' a small village/town in mostly negative ways. The economic status of displaced urbanites is mainly represented in the literature as lower class and lower-middle class (Atkinson 2000). This study reveals, however, that in a context of a further gentrifying city, highly educated people with moderate to high incomes (two jobs) suffer also from displacement. The group of displaced families experiences a push out of the city (against their will) without strong positive pulls from their new residential environment.

The third type of family-happy movers - have always known that they would like to leave the city after they had children. They are inclined to follow the traditional route of family formation and counterurbanisation, including suburbanisation. Happy movers feel pushed by anti-urban feelings related to the discourse of the city as an urban jungle for children (Emmelkamp 2004). Simultaneously, they feel pulled by a strong attraction to greener, more spacious, and smaller-scale environments resembling the rural idyll. In their new environment they feel free from the ever-demanding city. They are happy that they could make a next step in their housing career. This type of families resemble the antiurbanites described by Mitchell (2004); however, the label anti-urbanite is too strong for two reasons. First, these parents have been living in the capital for many years, and according to the interviews: with pleasure. They cannot be labelled as anti-urban and would probably not have moved out if they did not have children. Second, their new place of residence is not as remote as the literature on anti-urbanism suggests. In the context of the Netherlands, remote countryside is rare. To some extent the whole of the Netherlands can be considered to be urbanised, be it in different degrees.

With this small-scale research, we are modest in adding adjustments to the literature. Nevertheless, we want to share some new insights. First, in this study, we discover that, contrary to the literature, settled people do move (Fischer and Malmberg 2001), particularly in the context of a very tight housing market, such as the current market in Amsterdam. Second, the outmigration of families is considered to be related to a habitus informed by high economic capital (Boterman 2012). But this study reveals that also families with high cultural capital are among the families that leave the city. The backgrounds of the families of each of the three distinguished types did not reveal significant differences with respect to their educational and professional disciplines. Third, we could not identify a contrast between families that sought bigger housing and families that left due to their antiurban feelings (Aner 2016). For all interviewed families, the first incentive to leave the city was to get a bigger house. However, beneath this shared 'sameness', a differentiation of spatial discourses on good childhoods has been revealed. Fourth, this study reveals the importance of time-spatial ties for working families. We already know that the main motive for a family to live urban is related to a search for short travel times (Jarvis 2005; Hjorthol and Bjornskau 2005; Karsten 2007). Families belonging to the first two types search for new housing within the daily urban system in order to be able to combine care and career in their everyday life. The third type of the happy movers shows that moving out over bigger distances indeed goes along with mothers scaling back on work (becoming free-lance) and a higher dominance of the car in their new everyday life (Tillberg 2002).

We conclude this paper with a short discussion of the findings for cities. Settled family outmigration means a loss not only for some of the families that are engaged but also for the city. This research shows that the city loses families and with them, resources and 
networks. Many families had warm feelings for their former city (Amsterdam) and were actively engaged in many networks. The city could have taken measures to prevent outmigration of at least some of the pragmatic movers and all of the displaced families. The supply of affordable family housing in urban haven streets requires further attention. Displacement is not only a class-related process but also a process that affects diversity in terms of age and household situation. Family needs should be part of future building programs. Without specific attention, Amsterdam is at risk of becoming a city for the young, childless and rich (Siedentop et al. 2018; Barlindhaug 2018).

Acknowledgements This research project has been part of a (research) master project supervised by the author of this paper. I thank the enthusiastic contribution by Jana Pasker, Yte Schukking, Marieke van der Star, and particularly, Lisette van Rhijn and Karli Swart.

Open Access This article is licensed under a Creative Commons Attribution 4.0 International License, which permits use, sharing, adaptation, distribution and reproduction in any medium or format, as long as you give appropriate credit to the original author(s) and the source, provide a link to the Creative Commons licence, and indicate if changes were made. The images or other third party material in this article are included in the article's Creative Commons licence, unless indicated otherwise in a credit line to the material. If material is not included in the article's Creative Commons licence and your intended use is not permitted by statutory regulation or exceeds the permitted use, you will need to obtain permission directly from the copyright holder. To view a copy of this licence, visit http://creativecommons.org/licenses/by/4.0/.

\section{References}

Aner, L. (2016). Dwelling habitus and urban out-migration in Denmark. European Urban and Regional Studies, 23(4), 662-676.

Atkinson, R. (2000). The hidden costs of gentrification: displacement in central London. Journal of Housing and the Built Environment, 15(4), 307-326.

Authier, J., \& Lehman-Frisch, S. (2013). Le gout des Autres: Gentrification told by children. Urban Studies, 50(5), 994-1010.

Barlindhaug, R. \& B. Langset, M. Nygaard, M. Ekne Ruud (2018) Moving and staying motives of young Oslo families with children. Oslo: NIBR report 14.

Bell, W. (1968). The city, the suburb and a theory of residential choice. In S. Greer, et al. (Eds.), The new urbanization (pp. 132-168). New York: St. Martin's Press.

Booi, H. \& Karsten, L. (2019). Gezinnen in Amsterdam. Gaan ze weg of wie blijven toch? Amsterdam: Factsheet OiS (forth coming).

Boterman, W. (2012). Residential practices of middle classes in the field of parenthood. Amsterdam: UvA.

Boterman, W., Karsten, L., \& Musterd, S. (2010). Gentrifiers settling down? Patterns and trends of residential location of middle-class families in Amsterdam. Housing Studies, 25(5), 693-714.

Bourdieu, P. (1984). Distinction. Cambridge: Harvard University Press.

Brunt, L. (1974). Stedeling op het platteland. Meppel: Boom.

Butler, T. (2003). London calling. The middle classes and the remaking of inner-London. Oxford: Berg.

Elias, N., \& Scotson, J. (1994). The established and the outsiders. London: Sage.

Emmelkamp, R. (2004). Een veilig avontuur. Amsterdam: University of Amsterdam.

Fischer, P. A., \& Malmberg, G. (2001). Settled people don't move: On life course and (im-) mobility in Sweden. International Journal of Population Geography, 7(5), 357-371.

Frank, S., \& Weck, S. (2018). Being good parents or being good citizens? International Journal of Urban and Regional Research, 42(1), 20-35.

High, S., Goulet, L., Duchesneau, M., \& Guay, D. (2019) Interlocking lives. International Journal of Urban and Regional Studies. https://doi.org/10.1111/1486-2427.12728.

Hjorthol, R., \& Bjornskau, T. (2005). Gentrification in Norway: Capital, culture or convenience? European Urban and Regional Studies, 12, 353-371.

Jarvis, H. (2005). Work/life city limits. Comparative household perspectives. Hampshire: Palmgrave.

Karsten, L. (2007). Housing as a way of life: towards an understanding of middle class families preference for an urban residential location. Housing Studies, 22(1), 83-98. 
Karsten, L. (2014). From Yuppies to Yupps: family gentrifiers consuming spaces and re-inventing cities. TESG, 105(2), 175-188.

Lilius, J. (2014). Is there room for families in the inner-city? Life-stage blenders challenging planning. Housing Studies, 29(6), 843-861.

Mazanti, B. (2007). Choosing residence, community and neighbours -theorizing families' motives for moving. Geografiska Annaler, 89(1), 53-68.

Mitchell, C. J. (2004). Making sense of counterurbanization. Journal of rural studies, 20(1), 15-34.

Mulder, C. H., \& Hooimeijer, P. (1999). Residential relocations in the life course. In Population issues (pp. 159-186). Springer, Dordrecht.

Pinkster, F., \& Boterman, W. (2017). When the spell is broken: gentrification, urban tourism and the privileged discontent in the Amsterdam canal district. Cultural Geographies, 24(3), 457-472.

Rerat, P. (2012). The new demographic growth of cities: the case of reurbanisation in Switserland. Urban Studies, 49(5), 1107-1125.

Richards, L. (1990). Nobody's home. Dreams and realities in a new suburb. Oxford: Oxford University Press.

Rivera Escribano, M. (2007). Migration to rural Navarre: questioning the experience of counterurbanisation. TESG, 98(1), 32-41.

Siedentop, S., Zakrzewski, P., \& Storms, P. (2018). A childless urban renaissance? Regional Studies, Regional Science, 5(1), 1-20.

Solman, H. (2017). Alleviating tourist pressure from Amsterdam city centre by alternative food tourism in the neighbourhoods. Wageningen: Universiteit van Wageningen.

Sondermeijer, V. (2019). Onderzoek toont aan: Airbnb zorgt voor extra stijging woningprijzen. [online] NRC. https://www.nrc.nl/nieuws/2019/01/14/onderzoek-toont-aan-airbnb-zorgt-voor-extra-stijgingwoningprijzen-a3629009. Accessed 9 Feb 2019.

Tillberg, K. (2002). Children's (in)dependent mobility and parents'chauffering in the town and in the countryside. TESG, 93(4), 443-453.

Valentine, G. (1997). A safe place to grow up Parenting, perceptions of children's safety and the rural idyll. Journal of Rural Studies, 13(2), 137-148.

Publisher's Note Springer Nature remains neutral with regard to jurisdictional claims in published maps and institutional affiliations. 